以後放置

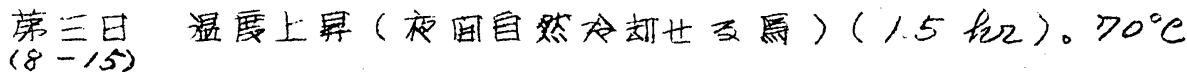

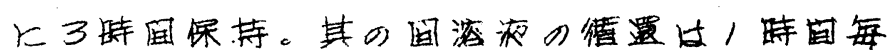

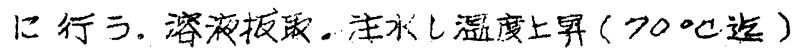

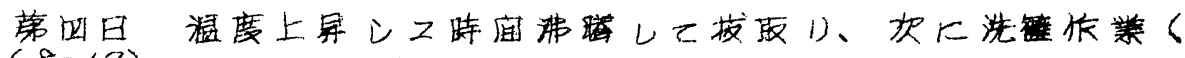

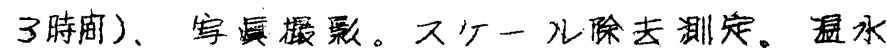
注入( / 時间)

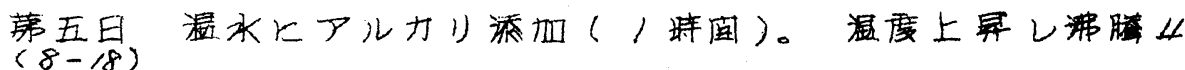

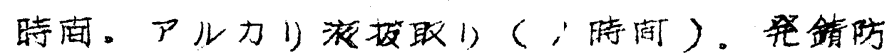
止作楞。酸洗作策终了。

\title{
[H]实験继果
}

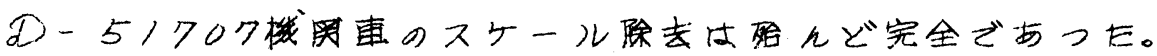

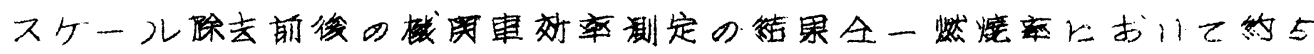
\%の㟟発力の增加を兒た。

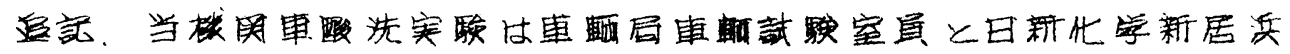

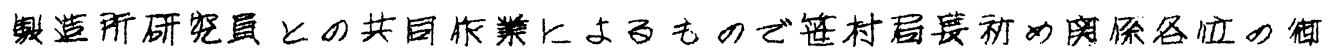

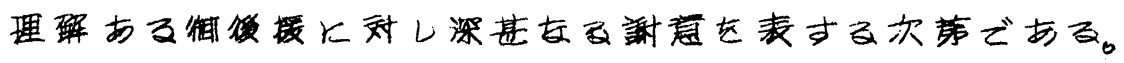

\section{燐酸ソーダ系市販清罐剂及び重合燐酸㙁 によるスケール並に膺蝕の防止}

\section{果日本重工大西正次}

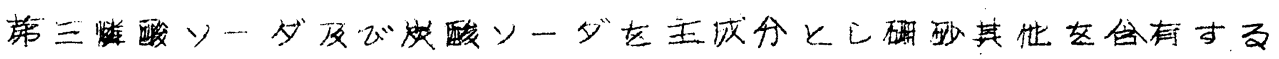

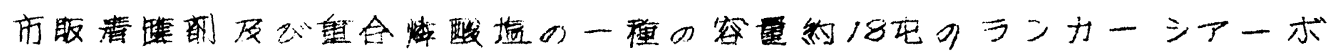

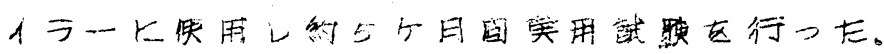


ボイラ一要目

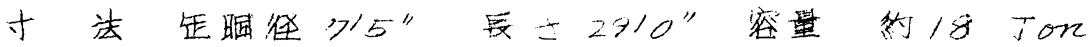

法秇西樜

㡡䏹径

以床面榜

然焼率

燃粈

給承
$70 \mathrm{~m}^{2}$

C. $84 m$

$2.96 \mathrm{mz}^{2}$

的 $150 \mathrm{~kg} / \mathrm{h}$

然田中境频
発笔

$3.2 \mathrm{~T} / \mathrm{H}$

快㳀正打的 $5 \mathrm{~kg} / \mathrm{cm}^{2}$

然丵方流手焚永平火格子

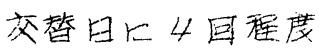

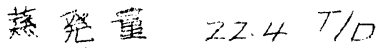

\begin{tabular}{|c|c|c|c|c|c|c|c|c|}
\hline 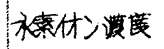 & 全国形分 & 塩素 & 硫酸 根 & 䂣 酰 & 族 & 分 & 硬度 & 反応 \\
\hline P & $78 \sim 64$ & Tor 40 & $68(504)$ & $19.8 \sim 18$ & 鼠大 & 1.4 & Z.1 & 中杵 \\
\hline
\end{tabular}

青跳成分(所敢回)

\begin{tabular}{|c|c|c|c|c|c|c|}
\hline アル力リ分 & 烧酸增 & 䨝硫酸 & 研础 & 有機物 & 办分 & 灯減 \\
\hline$\left(\mathrm{Na}_{2} \mathrm{CD}_{3} \mathrm{KL} \overrightarrow{\mathrm{C}}\right)$ (NaOH & $\left(P_{2} 05\right)_{\cup 2}(P$ & $\left(\mathrm{SO}_{\mathrm{Z}}, \mathbf{z}\right.$ & $\left(\begin{array}{r}\mathrm{Na} a_{2} B_{4} O_{7} \\
\angle L>\end{array}\right)$ & 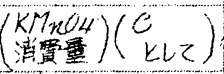 & & \\
\hline 27.00 & 263 & 0.50 & 7.04 & 8.23 & 17.63 & 5.62 \\
\hline
\end{tabular}

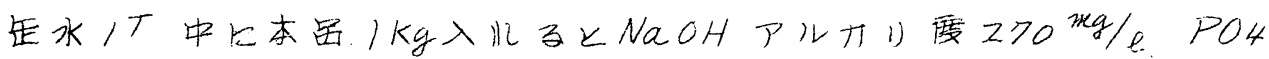

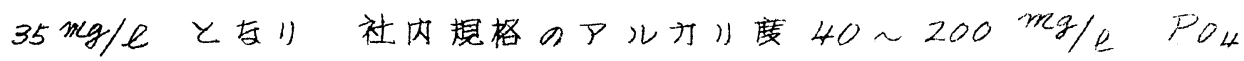
$15 \sim 40 \mathrm{mg} / \mathrm{l}$ 会格市及。

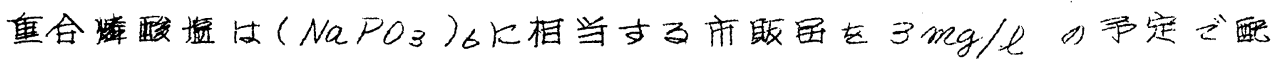

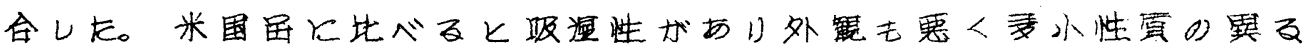
物とえら川る。

\begin{tabular}{|c|c|c|c|c|c|c|c|c|}
\hline & \multirow[b]{2}{*}{ 反応 } & \multirow{2}{*}{ 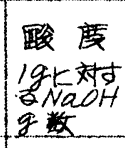 } & \multirow{2}{*}{ 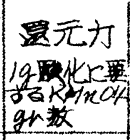 } & \multicolumn{2}{|c|}{ 全 蟆 } & \multirow{2}{*}{ 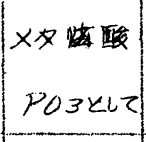 } & \multirow[b]{2}{*}{ 后欢 } & \multirow[b]{2}{*}{ 潇 } \\
\hline & & & & $\begin{array}{l}P_{2} 05 \\
\angle L 2\end{array}$ & $\begin{array}{l}P O L \\
\angle L Z\end{array}$ & & & \\
\hline Calgon & 不 明 & - & - & 67 & - & - & - & 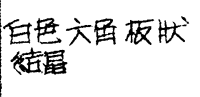 \\
\hline $\begin{array}{l}\text { USBoiler compo } \\
\text { ind. }\end{array}$ & 微酸制 & 0.1166 & 0.0213 & 6001 & 80.28 & 21.55 & ナシ & 公上 \\
\hline $\begin{array}{l}\text { Sodium Wexameto } \\
\text { Phosphate }\end{array}$ & 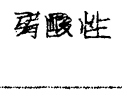 & 0.4160 & $\left(\begin{array}{l}00241 \\
43 P 03467 \\
321 \%\end{array}\right)$ & 75.29 & 10043 & 690 & " & $\begin{array}{l}\text { 無色吸误性の } \\
\text { 絃昆 }\end{array}$ \\
\hline
\end{tabular}

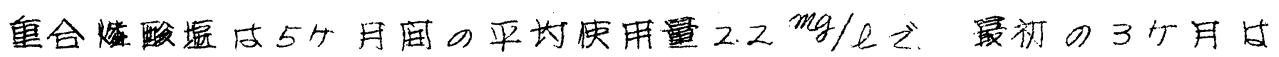

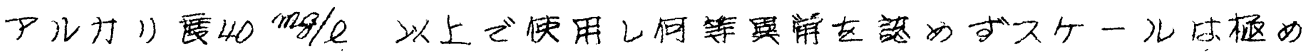




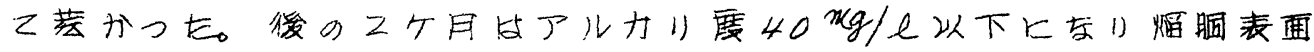

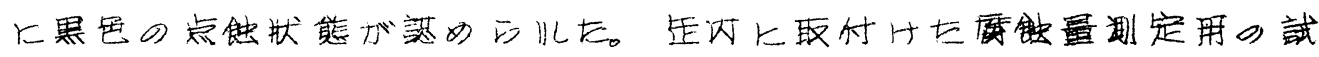

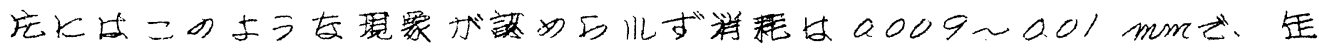

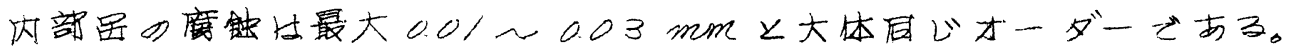

\begin{tabular}{|c|c|c|c|c|c|c|c|c|}
\hline 測定菌所 & $A$ & 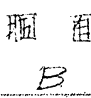 & 拊 & $F^{-}$ & 前部 $\frac{1}{A}$ & $\begin{array}{l}\text { 部 } \\
\text { 全D }\end{array}$ & 得部 $A$ & $\begin{array}{l}\text { 上 } \\
\text { 全 }\end{array}$ \\
\hline 浅䠶前厚 \pm & 518 & 430 & 553 & 535 & 12.22 & 12.30 & 12.01 & $12.28^{m m}$ \\
\hline " 校 & $5 / 8$ & $42 H$ & 552 & 5.33 & 12.18 & 12.28 & 12.00 & 12.24 \\
\hline 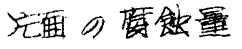 & 000 & 003 & DON5 & Dol & 002 & 001 & 0.005 & 002 \\
\hline
\end{tabular}

\begin{tabular}{|c|c|c|c|c|c|c|c|}
\hline & 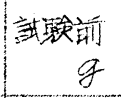 & $\begin{array}{r}\text { 裁壆原 } \\
g\end{array}$ & 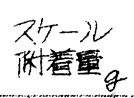 & 不尔次 & 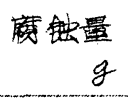 & $\frac{\Delta}{g} / m^{2}$ & $\frac{\Delta}{30 \mathrm{~m} / 57}$ \\
\hline 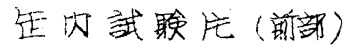 & 9630 & 975.0 & 12.0 & 958.7 & 143 & 79.6 & 0010 \\
\hline (中辇) & 16080 & 10.21 .0 & 130 & 10040 & 40 & 740 & 0.009 \\
\hline (後部) & 10240 & 1036.0 & 12.0 & - & & & \\
\hline
\end{tabular}

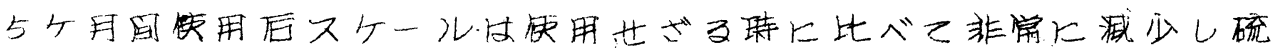

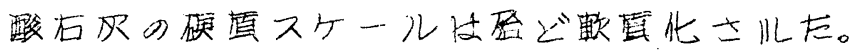

\begin{tabular}{|c|c|c|c|c|c|c|}
\hline & スケール上状 & $\mathrm{CaO}$ & $\mathrm{SiO}_{2}$ & 504 & $\operatorname{MgO}$ & $\mathrm{FeiO}_{3}$ \\
\hline 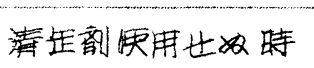 & 厚さ3〜5、硬萳 & $33.15=$ & 1990 & 4053 & 464 & $0.32 \%$ \\
\hline "矢用原 & $0.5 \sim 0.6^{2 \mathrm{~m} m} \cdot$ 颙直 & 2990 & 35.92 & 1.60 & 7.38 & 080 \\
\hline 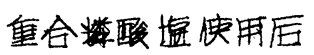 & $0.5^{22 m L}$ 程度、颗南 & 35.73 & 38.74 & $0 / 3$ & 453 & 0.80 \\
\hline
\end{tabular}

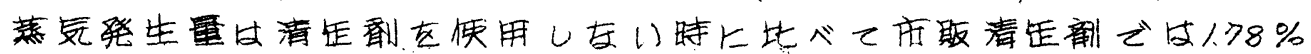

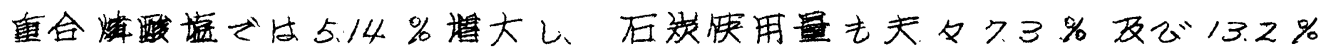
を减することができた。

\begin{tabular}{|c|c|c|c|c|c|c|c|}
\hline 稼動期间 & 清趾 & 实期国 & 嶚乫星 & 排水 & 石炭使用望 & 17 & 㬄 \\
\hline $26^{\text {年/月八 }}$ 月月 & $ナ \doteq$ & $131^{日}, 259.5^{1}$ & $\begin{array}{r}7 \\
3269.7\end{array}$ & セズ & $559.6^{\top}$ & $5.843(10 \%)$ & $04444(100 \%)$ \\
\hline 26年6月 次月 & 市骐呙 & 1.77 & 28766 & $1036^{\top}$ & 483.7 & $5947(101.78)$ & $a 411(92.7 \%)$ \\
\hline 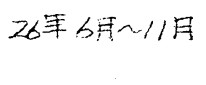 & $\begin{array}{l}\text { 重合酸 } \\
\text { 弶 }\end{array}$ & 11475 & 2711.9 & 147.2 & 441.9 & $6 / 36(105) 145)$ & $0.385(868 \%)$ \\
\hline
\end{tabular}

